\title{
STRATEGI PENINGKATAN INTERNASIONALISASI PADA UKM KERAJINAN KAYU DI KABUPATEN GIANYAR
}

\author{
Ni Nyoman Kerti Yasa ${ }^{1}$ \\ Wayan Yuniari ${ }^{2}$ \\ Rai Mutiara Sari ${ }^{3}$ \\ Anak Agung Diah Tarama Devi ${ }^{4}$ \\ Ida Ayu Agung Upadianti Jayantari ${ }^{5}$
}

\begin{abstract}
Fakultas Ekonomi dan Bisnis Universitas Udayana, Bali, Indonesia 1,2,3,4,5
Email: kertiyasa@unud.ac.id
\end{abstract}

\begin{abstract}
Strategies for Increasing Internationalization in Wood Craft SMEs in Gianyar Regency. This study discusses the opportunities, challenges, strengths and weaknesses of wood craft SMEs in Gianyar Regency, Bali. The results of the Assessment will be used as a basis for developing an internationalization improvement strategy. The analysis used in this research is SWOT Analysis and External Internal Matrix. The results showed that wood handicraft SMEs in Gianyar Regency had strengths and good opportunities in improving their international performance. Based on the existing environment, these SMEs are in a determined position (carefully). Therefore, a suitable business strategy to be developed is a Product Development strategy by focusing on developing product diversification, differentiating, branding of products, maximizing cooperation in shipping goods, and increasing the number of alternative suppliers, in order to improve international quality.
\end{abstract}

Keywords: SWOT analysis; business strategy; internationalization; UKM.

\begin{abstract}
Abstrak: Strategi Peningkatan Internasionalisasi Pada UKM Kerajinan Kayu Di Kabupaten Gianyar. Penelitian ini bertujuan untuk mengidentifikasi peluang, ancaman, kekuatan, dan kelemahan dari UKM kerajinan kayu di Kabupaten Gianyar, Bali. Hasil identifikasi tersebut akan digunakan sebagai dasar pengembangan strategi peningkatan internasionalisasi. Pendekatan yang digunakan dalam penelitian ini adalah dengan Analisis SWOT dan Matrik Internal Eksternal. Hasil penelitian menunjukkan bahwa UKM kerajinan kayu di Kabupaten Gianyar memiliki kekuatan dan peluang yang baik dalam meningkatkan kinerja internasionalnya. Berbasis dari kondisi lingkungan yang ada, UKM ini berada pada posisi Pertumbuhan (dengan hati-hati). Oleh karena itu, strategi bisnis yang cocok untuk dikembangkan adalah startegi Product Development dengan memfokuskan pada pengembangan keragaman produk, melakukan diferensiasi, branding terhadap produk, memaksimalkan kerjasama dalam pengiriman barang, serta menambah alternative jumlah pemasok, guna meningkatkan kinerja internasionalnya.
\end{abstract}

Kata Kunci: analisis SWOT; strategi bisnis; internasionalisasi; UKM. 


\section{PENDAHULUAN}

Usaha Kecil dan Menengah (UKM) mempunyai peranan penting dan strategis dalam memajukan perekonomian nasional (Moloud et al., 2016; Ayandibu and Houghton, 2017; Chimucheka, 2013). Peran penting dan strategis UKM dapat dilihat secara nyata melalui kontribusinya dalam memperluas dan meratakan kesempatan usaha, menyerap tenaga kerja, hingga mempercepat pertumbuhan ekonomi daerah maupun nasional (Okpara, 2011; Chandrarin et al., 2018; Tricahyadinata, 2013). UKM dengan berbagai kelebihannya juga telah berkembang jauh di pasar luar negeri dengan berinvestasi dalam pengembangan merek mereka sendiri (Chelliah et al., 2010). Oleh karena itu, UKM sangat layak untuk diperhitungkan di pasar internasional (Cahyadi, 2015). Melakukan internasionalisasi juga memungkinkan UKM untuk dapat bertahan di tengah persaingan yang ketat (Assaf et al., 2012; Click and Harrison, 2000; Goerzen and Beamish, 2003 ; Hsu and Pereira, 2008)

Salah satu UKM yang terkenal dan diakui keunggulannya di pasar internasional adalah UKM kerajinan kayu di Kabupaten Gianyar, Provinsi Bali (Nina, 2014). Saat ini,
UKM kerajinan kayu di Kabupaten Gianyar tidak hanya menjual produknya di dalam negeri, tetapi juga dijual ke banyak negara. Adapun negara yang menjadi tujuan ekspor dari produk olahan kayu Kabupaten Gianyar antara lain, Amerika Serikat, Jerman, Swedia, Australia, Perancis, Kanada, Inggris, dan beberapa negara lainnya (Gayatri dan Setiawina, 2016).

Walaupun kontribusi UKM untuk pembangunan pada umumnya diakui, namun pengusaha selalu dihadapkan dengan banyak kendala yang membatasi pertumbuhan dan kelangsungan hidup bisnis mereka (Garcia et al., 2018; Okpara, 2011; Tang and Hull, 2012; Nieto et al., 2015; Gentry et al., 2013). Terbukti, berdasarkan informasi dari penelitian awal dengan melakukan wawancara pada empat orang pebisnis UKM kerajinan kayu di Kabupaten Gianyar, diperoleh informasi bahwa saat ini UKM kerajinan kayu di Kabupaten Gianyar mengalami penurunan tingkat internasionalisasi yang dicerminkan dari penurunan penjualan ekspornya.

Berhasil atau tidaknya internasionalisasi bagi UKM tentu disebabkan oleh banyak faktor (Zhang et al., 2016; Knight and Liesch, 2016; Dimitratos et al., 2016). 
Faktor tersebut terdiri atas faktor eksternal dan internal perusahaan (Arsic et al., 2017; Budi et al., 2016; Verjel and Schmid, 2015). Faktor eksternal bisa memberikan peluang dan sebaliknya bisa menjadi ancaman. Faktor internal bisa menjadi sumber kekuatan atau bahkan bisa menjadi sumber kelemahan perusahaan (Khatri and Metri,2016; De et al., 2018; Bhamra et al., 2018; Frese et al., 2016). Berbasis pada peluang, ancaman, kekuatan dan kelemahan, perusahaan bisa mengembangka strategi bisnisnya yang cocok dalam rangka meningkatkan capaian kinerja khususnya peingkatan internasionalisasi (Carlsen, 2011; Antony, 2012; Helms et al., 2011).

Kajian tentang perumusan strategi bisnis berbasis Analisis SWOT telah banyak dikaji oleh peneliti sebelumnya antara lain (Rangkuti, 2014; Zhang et al., 2016; Knight and Liesch, 2016; Dimitratos et al., 2016; Khatri and Metri, 2016; De et al., 2018; Bhamra et al., 2018; Frese et al., 2016). Menurut Rangkuti (2014) analisis SWOT didasarkan pada logika yang dapat memaksimalkan kekuatan dan peluang, namun secara bersamaan dapat meminimalkan kelemahan dan ancaman dan dapat digunakan untuk merumuskan strategi perusahaan. Berdasarkan permasalahan tersebut, maka tujuan penelitian ini adalah untuk mengidentifikasi peluang, ancaman, kekuatan, dan kelemahan, yang dimiliki oleh UKM kerajinan kayu di Kabupaten Gianyar serta untuk mengembangkan strategi bisnis yang cocok guna meningkatkan internasionalisasi UKM kerajinan kayu di Kabupaten Gianyar.

Analisis SWOT. Analisis SWOT merupakan analisis yang membahas mengenai kekuatan, kelemahan, peluang, dan ancaman yang paling sering digunakan dalam perencanaan strategis (Rangkuti, 2014; Zhang et al., 2016; Knight and Liesch, 2016; Bhamra et al., 2018; Frese et al., 2016; Helms et al., 2011; Babaesmailli et al., 2012; Busaidi, 2014). Para peneliti dalam manajemen strategis setuju bahwa analisis SWOT memberikan dasar untuk realisasi penyelarasan yang diinginkan dari masalah organisasi (Evans and Wright, 2009; Rangkuti, 2014; Zhang et al., 2016; Bhamra et al., 2018; Frese et al., 2016; Helms and Nixon, 2010; Antony, 2012; Wang and Ma, 2018; Yuksel, 2012). Proses formulasi strategis dilakukan melalui tiga tahap analisis, yaitu tahap input, tahap analisis, dan tahap pengambilan keputusan. 
Menurut Weihrich mengungkapkan bahwakeajaiban SWOT adalah pencocokan faktor internal dan eksternal yang spesifik, yang menciptakan matriks strategis, yang masuk akal; faktor internal berada dalam kendali organisasi dan faktor eksternal berada di luar kendali organisasi. Keempat kombinasi tersebut disebut SO (Strength-Opportunity), WO (Weakness Opportunity), WT (WeaknessThreat), dan ST (Strength-Threat).

External Factors Analysis Summary (EFAS) dan Internal Factors Analysis Summary (IFAS). Menurut Hannah et al. (2011), External Factor Analysis Summary berkaitan dengan faktor sosial, teknologi, ekonomi, lingkungan, dan perspektif politik yang dapat diidentifikasi melalui brainstorming di antara para pembuat strategi di perusahaan. Faktor eksternal yang menguntungkan bagi organisasi adalah peluangnya dan yang tidak menguntungkan adalah ancamannya. Menurut Hannah et al. (2011), Internal Factor Analysis Summary, berkaitan dengan kelemahan atau kekuatan internal perusahaan yang dapat diubah, dikendalikan, atau dimanipulasi oleh perusahaan tersebut. Sebuah matriks IFAS dapat dibuat untuk mengetahui faktor internal mana yang dianggap relatif penting dan kurang penting yang merupakan kekuatan dan kelemahan perusahaan dan harus dijadikan prioritas dalam pertimbangan keputusan strategi.

Internasionalisasi. Melakukan internasionalisasi memungkinkan UKM untuk dapat bertahan di tengah persaingan yang ketat (Assaf et al., 2012). Internasionalisasi didefinisikan sebagai sejauh mana perusahaan terlibat dalam bisnis internasional. Ini termasuk ekspor, kehadiran anak perusahaan asing, kepemilikan saham oleh orang asing dan penunjukan orang asing dalam struktur organisasi (Chelliah et al., 2010). Jangkauan internasionalisasi bagi UKM mengacu pada sejauh mana daerah yang mampu dijangkau oleh UKM di seluruh dunia (Lu and Beamish, 2001).

Internasionalisasi terdiri banyak aktivitas termasuk ekspor, lisensi, dan Foreign Direct Investment (FDI). Mencari peluang dan menjual di pasar luar negeri adalah yang paling sering dan penting dari aktifitas perusahaan yang baru memulai internasionalisasi (Filatotchey et al., 2001 ; Zhou et al., 2009, Hashim and Hassan, 2008).

Strategi Bisnis. Ekspor merupakan sarana penting atau sebagai salah satu cara untuk 
meningkatkan internasionalisasi dan globalisasi perusahaan (Zhao and Zou, 2002; Wang and Ma, 2018). Mengekspor adalah cara yang relatif mudah dan cepat bagi UKM untuk memasuki pasar luar negeri karena perusahaan tidak harus berurusan dengan kompleksitas pendirian anak perusahaan asing ( $\mathrm{Lu}$ and Beamish, 2006). Melalui ekspor, perusahaan tidak hanya mendapatkan akses cepat ke pasar luar negeri dengan biaya modal yang sangat sedikit tetapi juga memiliki kesempatan untuk mendapatkan pengalaman internasional yang berharga yang dapat digunakan sebagai batu loncatan untuk ekspansi internasional masa depan (Dikova et al., 2016). Untuk menjalankan kegiatan ekspor, tentunya tetap memperhatikan strategi bisnis yang tepat. Strategi bisnis memiliki banyak pilihan, dan salah satu strategi bisnis yang selalu mendapat perhatian pebisnis adalah strategi bauran pemasarannya, yang mencakup produk, penentuan harga, promosi, dan distribusi.

\section{METODE PENELITIAN}

Penelitian ini dilakukan pada UKM kerajinan kayu di Kabupaten Gianyar. Sampel terdiri atas empat UKM yang telah melakukan internasionalisasi bisnis, minimal melakukan ekspor. Responden merupakan pengelola dan pembuat keputusan strategi pada UKM tersebut. Pengumpulan data menggunakan kuesioner dengan kolom jawaban yang berisi ukuran 5 tingkat Skala Likert.

Analisa lingkungan internal menggunakan pendekatan variabel pada bauran pemasaran yaitu product, price, place dan promotion, sedangkan analisis lingkungan eksternal yaitu dengan mengamati lingkungan makro dan industri. Teknik analisis data yang digunakan adalah analisis SWOT yang hasilnya dirangkum dalam Tabel External Factors Analysis Summary (EFAS) dan Tabel Internal Factors Analysis Summary (IFAS). Responden sebagai penyusun strategi bisnis memberikan persepsi mereka tentang bobot (besarnya pengaruh dari masingmasing faktor) dan memberikan rating untuk menggambarkan tentang jenis pengaruhnya, dan menghitung total nilai tertimbang yang digunakan sebagai dasar untuk menentukan peluang atau ancaman dari hasil analisis lingkungan eksternal (EFAS) dan kekuatan atau kelemahan dari hasil analisis lingkungan internal (IFAS). Langkah berikutnya mentransfer nilai EFAS dan IFAS ke dalam Matrik Internal - Eksternal untuk menentukan posisi bisnis 
sebagai dasar perancangan strategi bisnis yang cocok untuk meningkatkan internasionalisasi.

\section{HASIL DAN PEMBAHASAN}

Responden terdiri atas empat UKM kerajinan kayu di Kabupaten Gianyar yang diwakili oleh pemilik usaha yang sekaligus menjadi pembuat keputusan stratejik usahanya. Lokaksi UKM menyebar di berbagai daerah di Kabupaten Gianyar diantaranya: Peliatan, Mas, Tampaksiring dan kota Gianyar. Negara yang menjadi tujuan ekspor diantaranya Amerika, Australia, dan Singapura.

Adapun faktor internal dan eksternal yang dimiliki oleh UKM Kerajinan Kayu di Kabupaten Gianyar seperti terlihat pada Tabel 1 dan Tabel 2.

Berdasarkan Matriks IFAS - EFAS diperoleh jumlah skor IFAS adalah 3,65 dan skor EFAS adalah 3,54 dan ditransfer ke dalam Matrik I-E. Posisinya dapat dilihat pada Gambar 1.

Tabel 1.

Kekuatan dan Kelemahan dari UKM Kerajinanan Kayu di Kabupaten Gianyar

\begin{tabular}{llcccc}
\hline NO & Faktor Strategis Internal & Bobot & $\begin{array}{c}\text { Rating } \\
\text { / Nilai }\end{array}$ & $\begin{array}{c}\text { Nilai } \\
\text { Tertimbang }\end{array}$ & Keterangan \\
\hline 1 & Keragaman produk yang dijual & 0,07 & 3 & 0,21 & Lemah \\
2 & Kualitas produk yang dijual & 0,12 & 4 & 0,48 & Kuat \\
3 & Desain produk & 0,13 & 4 & 0,52 & Kuat \\
4 & Branding produk & 0,05 & 2 & 0,10 & Lemah \\
5 & Fleksibiltas harga & 0,10 & 4 & 0,40 & Kuat \\
6 & Fleksibilitas sistem Pembayaran & 0,10 & 4 & 0,40 & Kuat \\
7 & Maksimalisasi penggunaan & 0,05 & 2 & 0,10 & Lemah \\
& Teknologi informasi & 0,10 & 4 & 0,40 & Kuat \\
8 & Penjualan langsung & 0,10 & 4 & 0,40 & Kuat \\
9 & Lokasi toko & 0,10 & 4 & 0,40 & Kuat \\
10 & Memiliki banyak perantara penjualan & & & & Lemah \\
11 & Melakukan kerjasama terkait & 0,08 & 3 & 0,24 & \\
& pengiriman & 1,00 & & 3,65 & \\
\hline
\end{tabular}


Tabel 2.

Peluang dan Ancaman dari UKM Kerajinan Kayu di Kabupaten Gianyar

\begin{tabular}{|c|c|c|c|c|c|}
\hline NO & Faktor Strategis Eksternal & Bobot & $\begin{array}{l}\text { Rating / } \\
\text { Nilai }\end{array}$ & $\begin{array}{c}\text { Nilai } \\
\text { Tertimbang }\end{array}$ & Keterangan \\
\hline 1 & Adanya pesaing baru & 0,09 & 3 & 0,27 & Ancaman \\
\hline 2 & Adanya produk substitusi & 0,09 & 3 & 0,27 & Ancaman \\
\hline 3 & Perkembangan permintaan di pasar & 0,15 & 4 & 0,60 & Peluang \\
\hline 4 & Jumlah pemasok & 0,13 & 3 & 0,39 & Ancaman \\
\hline 5 & $\begin{array}{l}\text { Peraturan pemerintah Gianyar terkait } \\
\text { ekspor }\end{array}$ & 0,15 & 4 & 0,60 & Peluang \\
\hline 6 & Stabilitas nilai tukar mata uang & 0,15 & 4 & 0,60 & Peluang \\
\hline 7 & Pekembangan teknologi informasi & 0,09 & 4 & 0,36 & Peluang \\
\hline \multirow[t]{2}{*}{8} & $\begin{array}{l}\text { Transportasi (kemudahan dalam mengirim } \\
\text { barang ) }\end{array}$ & 0,15 & 3 & 0,45 & Ancaman \\
\hline & & 1,00 & & 3,54 & \\
\hline
\end{tabular}

Sumber : Hasil Pengolahan Data

\begin{tabular}{|c|c|c|c|c|c|}
\hline & \multicolumn{5}{|c|}{ Total Skor Strategi Internal } \\
\hline & & Sangat Kuat & Kuat & Lemah & Sangat Lemah \\
\hline \multirow{4}{*}{$\begin{array}{l}\text { Total } \\
\text { Skor } \\
\text { Strategi } \\
\text { Eksternal }\end{array}$} & & $4,00-5,00$ & $3,00-3,99$ & $2,00-2,99$ & $1,00-1,99$ \\
\hline & $\begin{array}{r}\text { Sangat } \\
\text { Berpeluang } \\
4,00-5,00\end{array}$ & $\begin{array}{l}\text { I GROWTH } \\
\text { (Konsentrasi melalui } \\
\text { integrasi vertikal) }\end{array}$ & $\begin{array}{l}\text { II GROWTH } \\
\text { (Konsentrasi melalui } \\
\text { integrasi horisontal) }\end{array}$ & $\begin{array}{l}\text { III STABILITY } \\
\text { (Dengan konsentrasi } \\
\text { internal) }\end{array}$ & $\begin{array}{c}\text { IV RETRECHMENT } \\
\text { (Turn Around Dengan } \\
\text { Down Sizing) }\end{array}$ \\
\hline & $\begin{array}{l}\text { Berpeluang } \\
3,00-3,99\end{array}$ & $\begin{array}{l}\text { V GROWTH } \\
\text { (Dengan Cepat) }\end{array}$ & $\begin{array}{l}\text { VI GROWTH } \\
\text { (Hati-Hati) }\end{array}$ & $\begin{array}{l}\text { VII STABILITY } \\
\text { (Dengan Integrasim } \\
\text { Interna) }\end{array}$ & $\begin{array}{c}\text { VIII RETRECHMENT } \\
\text { (Penciutan) }\end{array}$ \\
\hline & $\begin{array}{c}\text { Mengancam } \\
2,00-2,99\end{array}$ & $\begin{array}{c}\text { IX GROWTH } \\
\text { (Diversifiksi } \\
\text { Konsentrik) }\end{array}$ & $\begin{array}{c}\text { X GROWTH } \\
\text { (Diversifiksi } \\
\text { Konsentrik) }\end{array}$ & $\begin{array}{l}\text { XI STABILITY } \\
\text { (Diversifikasi } \\
\text { Konglomerat) }\end{array}$ & $\begin{array}{l}\text { XII RETRECHMENT } \\
\text { (Bangkrut dan } \\
\text { Likuidasi) }\end{array}$ \\
\hline & $\begin{array}{l}\text { Sangat } \\
\text { Mengancam } \\
1,00-1,99 \\
1,00\end{array}$ & $\begin{array}{l}\text { XIII GROWTH } \\
\text { (Diversifiksi } \\
\text { Konsentrik) }\end{array}$ & $\begin{array}{l}\text { XIV GROWTH } \\
\text { (Diversifiksi } \\
\text { Konsentrik) }\end{array}$ & $\begin{array}{l}\text { XV STABILITY } \\
\text { (Diversifikasi } \\
\text { Konglomerat) }\end{array}$ & $\begin{array}{l}\text { XVI RETRECHMENT } \\
\text { (Bangkrut dan } \\
\text { Likuidasi) }\end{array}$ \\
\hline
\end{tabular}

Sumber : Hasil Pengolahan Data

\section{Gambar 1. Matriks Internal - Eksternal}


Berdasarkan Gambar 1 (Matriks Internal - Eksternal) dapat dinyatakan bahwa UKM kerajinan kayu di Kabupaten Gianyar berada pada posisi Growth (dengan hati-hati). Posisi yang sedang bertumbuh tentu didukung oleh kondisi internal UKM yang memiliki beberapa kekuatan. Kekuatan tersebut diantaranya mampu menjual produk yang berkualitas, memiliki desain produk yang unik dan berciri khas Bali, sangat fleksibel dalam kesepakatan harga dan sistem pembayaran sehingga sangat memungkinkan bagi pembeli untuk menawar harga. Kekuatan lainnya yaitu UKM ini berada pada lokasi strategis yang memungkinkan terjadinya penjualan langsung secara rutin, didorong lagi dengan memiliki banyak perantara penjualan yang dapat meningkatkan penjualan. Tentunya kekuatan-kekuatan inilah yang mampu meningkatkan kinerja internasionalisasi sehingga berada pada posisi pertumbuhan.

Pertumbuhan yang dialami UKM kerajinan kayu di Kabupaten Gianyar ini masih tergolong dalam fase yang hati-hati. Hal ini disebabkan karena kelemahan yang harus ditangani guna meningkatkan kinerja internasionalisasi. Adapun kelemahan yang dimiliki yaitu produk yang dijual masih kurang beragam bahkan cenderung mirip dan sama dengan pesaingnya, mayoritas dari UKM tidak melakukan branding terhadap produknya, dan tidak memanfaatkan dengan maksimal teknologi informasi khususnya untuk kegiatan pemasaran, serta belum maksimal dalam melakukan kerjasama dalam pengiriman barang. Oleh karena itu, tidak dipungkiri, kelemahan yang dimiliki UKM inilah yang membuatnya berada pada fase pertumbuhan yang berhati-hati. Ke depan, UKM kerajinan kayu di Kabupaten Gianyar harusnya melakukan promosi melalui media sosial. Hal seperti ini sudah menjadi bukti bahwa peningkatan kinerja perusahaan bisa dilakukan melalui promosi media sosial (Yasa et al., 2020)

UKM kerajinan kayu di Kabupaten Gianyar harus mampu meningkatkan pertumbuhannya dengan memanfaatkan peluang yang ada. Adapun peluang tersebut yaitu adanya perkembangan permintaan di pasar dimana produk yang diinginkan konsumen tidak hanya sebatas pada produk kerajinan kesenian, melainkan juga produk kayu untuk kegiatan sehari-hari. Peluang lainnya yaitu peraturan pemerintah yang mendorong peningkatan dan kemudahan ekspor barang, stabilitas nilai tukar 
mata uang, perkembangan teknologi informasi yang pesat dapat digunakan untuk mendukung bisnis seperti pada bidang pemasaran. Peluangpeluang tersebut tentu harus dimanfaatkan guna meningkatkan kinerja internasionalisasi

Fase pertumbuhan (hati-hati) yang dialami UKM kerajinan kayu di Kabupaten Gianyar juga disebabkan oleh ancaman yang dihadapinya. Adapun ancaman tersebut diantaranya bermunculannya pendatang baru dan tersebarnya produk substitusi, jumlah pemasok yang kadang terbatas, dan masih belum maksimal dalam akses pengiriman barang. Tentu ini menjadi ancaman dan rambu hati-hati bagi UKM agar dapat mengantisipasi ancaman yang ada. Berbabis pada posisi pertumbuhan (hati-hati) yang dialami oleh UKM kerajinan kayu di Kabupaten Gianyar, maka sangat diperlukan penyusunan strategi yang dapat mendukung pertumbuhan yang lebih baik yang tentunya juga mendorong peningkatan kinerja internasionalisasi.

\section{SIMPULAN DAN SARAN}

Berdasarkan analisis terhadap lingkungan UKM kerajinan kayu di Kabupaten Gianyar, baik lingkungan internal maupun eksternal, diperoleh simpulan sebagai berikut: 1). Faktor internal yang menjadi kekuatan utama UKM kerajinan kayu di Kabupaten Gianyar yaitu; kualitas produk yang dijual, desain produk, fleksibilitas harga, fleksibilitas sistem pembayaran, penjualan langsung, lokasi toko, banyaknya perantara penjualan; sedangkan kelemahan utama UKM kerajinan kayu di Kabupaten Gianyar yaitu: keragaman produk yang dijual, branding produk dan maksimalisasi penggunaan teknologi informasi, dan kerjasama terkait pengiriman barang. 2). Faktor eksternal yang menjadi peluang utama UKM kerajinan kayu di Kabupaten Gianyar adalah : perkembangan permintaan di pasar, peraturan pemerintah Gianyar terkait ekspor, stabilitas nilai tukar mata uang, dan perkembangan teknologi informasi ; sedangkan yang menjadi ancaman utama UKM kerajinan kayu di Kabupaten Gianyar adalah : adanya pesaing baru, adanya produk subsitusi, jumlah pemasok yang masih terbatas, dan akses pengiriman barang belum maksimal. 3). Berdasarkan analisis matriks IFAS diperoleh total skor internal sebesar 3,65 dan oleh karena total skor tersebut bernilai di atas rata-rata, yaitu di atas 3,0 ini menunjukan bahwa secara umum, UKM kerajinan kayu di 
Kabupaten Gianyar memiliki kekuatan untuk melakukan internasionalisasi. 4). Berdasarkan analisis matriks EFAS diperoleh total skor eksternal sebesar 3,54 dan oleh karena total skor tersebut bernilai di atas rata-rata, yaitu di atas 3,0 maka menunjukan UKM kerajinan kayu di Kabupaten Gianyar memiliki peluang yang baik dalam upayanya meningkatkan kinerja internasionalisasi. 5). Berdasarkan pemetaan pada Matriks I-E diperoleh posisi UKM kerajinan kayu di Kabupaten Gianyar secara internal dan eksternal berada pada sel VI yaitu Strategi Growth dengan hati-hati.

Berdasarkan hasil analisis SWOT, matriks IFAS, Matrik EFAS, dan Matrik Internal-Eksternal, disarankan agar UKM kerajinan kayu di Kabupaten Gianyar melakukan strategi Product Development. Berikut merupakan beberapa cara yang dapat ditempuh : 1). Sebaiknya UKM kerajianan kayu di Kabupaten Gianyar lebih memperbanyak lagi keragaman produk yang dijual mengingat permintaan konsumen akan berubah sering dengan waktu sehingga keragaman ini akan membuat konsumen akan tetap tertarik pada produk kerajinan kayu. 2). Sebaiknya produk yang dijual memiliki keunikan yang tersendiri yang membedakannya dari produk pesaing sehingga keunikan tersebut menjadi suatu produk dengan branding yang selalu diingat oleh konsumen. 3). Seiring dengan perkembangan teknologi yang semakin pesat menyebabkan UKM kerajinanan kayu harus mengikuti cepatnya perkembangan teknologi agar tidak terlambat dan tertinggal mengikuti perkembangan teknologi. Salah satu cara yang dapat dilakukan adalah dengan membuat web site atau berjualan di platform e-commerce dan menggunakan media sosial. 4). Upaya yang digunakan untuk menghadapi adanya pesaing baru adalah dengan menciptakan keunggulan kompetitif misalnya dapat dilakukan dengan menciptakan kreasi-kreasi baru yang unik atau dengan diferensiasi saluran pemasaran

\section{REFERENSI}

Antony Jiju. (2012). A SWOT analysis on Six Sigma: some perspectives from leading academics and practitioners, International Journal of Productivity and Performance Management, Vol. 61 No. 6, pp. 691-698.

Arsić, S., Nikolić, D., and Živković, Ž. (2017). Hybrid SWOT - ANP - FANP model for prioritization strategies of sustainable development of ecotourism in National Park Djerdap, Serbia. Forest Policy and Economics, Vol. 80. pp. 11-26.

Assaf A.G., Alexander J., Brian T.R., Carlos P.B. (2012). Internationalization and Performance of Retail Firms : A Bayesian Dynamic Model. Journal of Retailing, Vol. 88 No. 2, pp. 191-205. 
Ayandibu A.O. and Houghton J. (2017), The role of Small and Medium Scale Enterprise in local economic development (LED), Journal of Business and Retail Management Research (JBRMR), Vol. 11 No.2, pp. 133-139

Babaesmailli, M., Arbabshirani, B. and Golmah, V. (2012), Integrating analytical network process and fuzzy logic to prioritize the strategies: a case study for tile manufacturing firm, Expert Systems with Applications, Vol. 39 No. 1, pp. 925-935.

Bhamra, T., Hernandez, R. J., Rapitsenyane, Y., and Trimingham, R. (2018). Product Service Systems: A Sustainable Design Strategy for SMEs in the Textiles and Leather Sectors. She Ji, The Journal of Design, Economics, and Innovation, Vol. 4 No. 3, pp. 229-248.

Budi, I., Bhayangkara, W. D., and Fadah, I. (2016). Identification of Problems and Strategies of the Home-Based Industry in Jember Regency. Agriculture and Agricultural Science Procedia, Vol. 9, pp. 363-370.

Busaidi, K.A.A. (2014). SWOT of social networking sites for group work in government organizations: An exploratory Delphi study from IT managers' perspective, VINE: The journal of information and knowledge management systems, Vol. 44 No. 1, pp. $121-139$.

Cahyadi, Indra. (2015). Tantangan Internasionalisasi UKM di Indonesia dalam Menghadapi Masyarakat Ekonomi ASEAN. Kajian. Vol. 20 No. 2, Hal. 129-143.

Carslen J. Dan Anderson T.D. (2011). Strategic SWOT analysis of public, private and not-for-profit festival organisations. International Journal of Event and Festival Management Vol. 2 No. 1, pp. 83-97.

Chandrarin, G., Sanusi, A., Imron, A., and
Yuniarti, S. (2018). An empirical study on income equality, economic growth and financial inclusion in Indonesia: model development on SMEs financing. International Journal of Education Economics and Development, Vol. 9 No. 4, pp. 346-358.

Chelliah, S., Pandian, S., Sulaiman, M., and Munusamy, J. (2010), The Moderating Effect of Firm Size: Internationalization of Small and Medium Enterprises (Smes) in The Manufacturing Sector, African Journal of Business Management, Vol. 4, pp. 3096-3109

Chimucheka, T. (2013). Overview and Performance of the SMMEs Sector in South Africa. Mediterranean Journal of Social Sciences, Vol. 4 No. 14, pp.783795.

Click, Reid. W and Paul Harrison (2000), Does Multinationality Matter? Evidence of Value Destruction in U.S. Multinational Corporations, working paper 21, US Federal Reserve Board.

De, D., Chowdhury, S., Dey, P. K., \& Ghosh, S. K. (2018). Impact of Lean and Sustainability oriented innovation on Sustainability performance of Small and Medium Sized Enterprises: A Data Envelopment Analysis-based Framework. International Journal of Production Economics.

Dikova, D., Jaklič, A., Burger, A., and Kunčič, A. (2016). What is beneficial for firsttime SME-exporters from a transition economy: A diversified or a focused export-strategy?, Journal of World Business, Vol. 51 No. 2, pp. 185-199.

Dimitratos, P., Johnson, J. E., Plakoyiannaki, E., and Young, S. (2016). SME internationalization: How does the opportunity-based international entrepreneurial culture matter?, International Business Review, Vol. 25 No. 6 
Evans, C. and Wright, A. (2009), How to conduct a SWOT analysis, The British Journal of Administrative Management. Vol 24, pp. 10-34.

Filatotchev, I., Dyomina, N., Wright, M., and Buck, T. (2001). Effects Oof PosPrivatization Governance and Strategies on Export Intensity in The Former Soviet Union, Journal of International Business Studies, Vol. 32 No.4, pp. 853871.

Frese, M., Hass, L., and Friedrich, C. (2016). Personal initiative training for small business owners, Journal of Business Venturing Insights, Vol. 5, pp. 27-36.

Garcia, E., Francisco, Paolo, Jamil., Caboverde., and Ed, Christopher. (2018). Entrepreneurial Orientation, Perceived Competitive Threat, and Competitive Strategy Among SMEs in an EmergingEconomy Capital, RSN-PCC Working Paper Vol. 18, No. 5.

Gayatri dan Setiawina. (2016). Analisis FaktorFaktor Yang Mempengaruhi Ekspor Produk Olahan Kayu Di Kabupaten Gianyar. E-Jurnal EP Unud, Vol. 5 No. 1, pp. 22-34

Gentry, R., Dalziel, T. and Jamison, M. (2013). Who Do Start-Up Firms Imitate? A Study of New Market Entries in the CLEC Industry, Journal of Small Business Management, Vol. 51 No. 4, pp. 525-538.

Goerzen, Anthony and Beamish Paul W. (2003), Geographic Scope and Multinational Enterprise Performance, Strategic Management Journal, Vol. 24 No. 13, pp. 1289-306.

Hannah Koo Ka-Yin., Chau Leung-Chi., Koo Songbai Liu., and Shu-Chuen Tsui, (2011), A structured SWOT approach to develop strategies for the government of Macau, SAR, Journal of Strategy and Management, Vol. 4 No. 1, pp. $62-81$

Hashim, M, K. and Hassan, R. (2008).
Internationalization of SMEs: options, incentives, problems and business strategy. Malaysian Management Review, Vol. 43 No. 1, pp. 63-76.

Helms, M. and Nixon, J. (2010), Exploring SWOT analysis - where are we now? a review of academic research from last decade, Journal of Strategy and Management, Vol. 3 No. 3, pp. 215251.

Helms, M., Rodriguez, M, A., Rios, L, D., \& Hargrave, W., (2011), Entrepreneurial potential in Argentina: a SWOT analysis, Comparative Review: An International Journal, Vol. 21 No. 3, pp. 269-287.

Hsu, Chin-Chun and Arun Pereira (2008), Internationalization and Performance: The Moderating Effects of Organizational Learning, Omega: The International Journal of Management Science, Vol. 36 No. 2, pp. 188-205.

Khatri, J. K. and Metri, B. (2016). SWOTAHP Approach for Sustainable Manufacturing Strategy Selection: A Case of Indian SME. Global Business Review, Vol. 17 No. 5, pp. 1211-1226.

Knight, G. A., \& Liesch, P. W. (2016). Internationalization: From incremental to born global. Journal of World Business, Vol. 51 No. 1, pp. 93-102.

Lu, J. W., and Beamish, P. W. (2006). SME internationalization and performance: Growth vs. profitability. Journal of International Entrepreneurship, Vol 4 No 1, pp. 27-48.

Moloud Suhaiza S., Zailani Mohammad., Iranmanesh Azmin., and Azliza Aziz , (2016), Motivations of SME entrepreneurs to become halalpreneurs, Journal of Science and Technology Policy Management, Vol. 7 No 2, pp. $173-189$

Nieto, M., Santamaria, L. and Fernandez, Z. (2015). Understanding the Innovation 
Behavior of Family Firms. Journal of Small Business Management, Vol. 53 No. 2, pp. 382-399.

Nina E. L. Ni Putu. (2014). Strategi Pemberdayaan Industri Kecil Kerajinan Produk olahan Kayu Di Kabupaten Gianyar Provinsi Bali (disertasi). Program Pascasarjana UNUD.

Okpara, John. (2011). Factors constraining the growth and survival of SMEs in Nigeria, Management Research Review, Vol. 34 No 2, pp. 156 - 171

Rangkuti, Freddy. (2014). Analisis SWOT: Teknik Membedah Kasus Bisnis. Jakarta: Gramedia Pustaka Utama

Tang, Z. and Hull, C. (2012). An Investigation of Entrepreneurial Orientation, Perceived Environmental Hostility and Strategy Application among Chinese SMEs. Journal of Small Business Management, Vol. 50 No. 1, pp. 132158.

Tricahyadinata, I. (2013) Kapabilitas inovasi usaha kecil dan menengah di Indonesia (Small and medium business innovation capability in Indonesia), Jurnal Akuntabel in Indonesian, Vol. 10, No. 1, pp.1-18.

Verjel, A.M., and Schmid, J. (2015). Possibilities of Increasing Business Sustainability in the Context of Globalization. The Case of the SMEs. Procedia Economics and Finance, Vol 32, pp 716-720.

Wang, W., and Ma, H. (2018). Export strategy, export intensity and learning: Integrating the resource perspective and institutional perspective. Journal of World Business, Vol 53 No 4, pp. 581-592.

Weihrich, H. (1982), The TOWS matrix \pm a tool for situational analysis, Journal of Long Range Planning, Vol. 15 No. 2.

Yasa Ni Nyoman Kerti, Adnyani I G. A. D, Rahmayanti, P. L. D. (2020), The
Influence Of Social Media Usage On The Perceived Business Value And Its Impact On Business Performance Of Silver Craft Smes In Celuk Village, Gianyar - Bali, Academy of Strategic Management Journal, Vol. 19, Issue 1, pp. 1-10.

Yuksel, I. (2012), An integrated approarch with group decision-making for strategy selection in SWOT analysis, International Journal of Research in Business and Sosial Science, Vol 2 No 11, pp. 34-161.

Zhang, X., Ma, X., Wang, Y., Li, X., and Huo, D. (2016). What drives the internationalization of Chinese SMEs? The joint effects of international entrepreneurship characteristics, network ties, and firm ownership. International Business Review, Vol 25 No 2.

Zhao, H., and Zou, S. (2002). The impact of industry concentration and firm location on export propensity and intensity: An empirical analysis of Chinese manufacturing firms. Journal of International Marketing, Vol 10 No 1, pp. 52-71.

Zhou, Kevin Zheng, James R. Brown and Chekitan S. Dev. (2009). Market Orientation, Competitive Advantage, and Performance: A Demand - Based Perspective. Journal of Business Research, Vol 62, pp. 1063 - 1070 